\title{
What is a discourse approach to Twitter, Facebook, YouTube and other social media: connecting with other academic fields?
}

Gwen Bouvier

To cite this article: Gwen Bouvier (2015) What is a discourse approach to Twitter, Facebook, YouTube and other social media: connecting with other academic fields?, Journal of Multicultural Discourses, 10:2, 149-162, DOI: 10.1080/17447143.2015.1042381

To link to this article: https://doi.org/10.1080/17447143.2015.1042381

曲 Published online: 15 Jun 2015.

Submit your article to this journal $\pi$

Џll Article views: 4233

View Crossmark data ¿

Citing articles: 18 View citing articles 


\title{
What is a discourse approach to Twitter, Facebook, YouTube and other social media: connecting with other academic fields?
}

\author{
Gwen Bouvier* \\ College of Communication and Media Studies and Zayed University
}

(Received 21 March 2015; accepted 3 April 2015)

\begin{abstract}
The wider field of discourse studies is still only beginning to turn its attention to social media despite a number of notable scholarly works. But as yet there has been little that has dealt specifically with issues of multicultural discourse - how language, identity, cross-cultural social relations and power play out in the rapidly evolving landscape of social media. In this paper, I show why discourse studies must engage with theories and empirical work on social media across academic fields beyond discourse studies and linguistics, at how these can help best frame the kinds of research that needs to be done, how to best formulate some of the basic questions of critical discourse analysis for this new communicative environment. I use this as a platform to point to the areas where multicultural discourse studies can work - where all the ambiguities of former studies of 'identity' and 'culture' are present, but realised in new ways. Yet these new forms of communication are fused into wider patterns of changing cultural values about forms of social structure, knowledge itself and the kinds of issues that tend to form our individually civic spheres.
\end{abstract}

Keywords: social media; discourse; Facebook; Twitter; YouTube; critical discourse analysis

\section{Introduction}

This special edition of Journal of Multicultural Discourses brings together a set of papers that take different approaches to the study of discourse and social media, with an emphasis on issues of culture and identity. Social media offer new challenges and new possibilities, and create new requirements for the study of multicultural discourses, for which, I want to show, we would be wise to engage across the scholarly work in a number of academic fields in order to help gauge priorities and to place our work well in the landscape of social media research.

The Journal of Multicultural Discourses can play an important role in promoting the role of culture in discourse studies, where social media now provide a site of fundamental shifts in communicative practices, genres and modalities. Such a contribution is important to offset the emphasis on work that tends to focus on the 'global centres', driven partly by the way that networks have tended to be driven by Anglo-American and English language academic publishing (Larsson 2009) with the consequent definitions of theories, concepts and prioritised topics (Shi 2013). The journal has aimed to foreground studies which help us to understand the ways in which different cultural communities interact

*Email: gwen.bouvier@gmail.com 
differently, in terms of worldviews, concepts, values, rules, strategies, means, channels, purposes and consequences. And in this introduction I want to make the case for why social media provide one central site where we can, and should, carry out this important work. Discourse studies should certainly have more to say about this, especially given the pace of processes of globalisation, where it is important to understand not only these worldviews in themselves but also the ways in which these interact and are in transformation. Social media are part of this, now fused into the fabric of everyday life, providing new possibilities for intercontinental communication, new ways of maintaining, creating, or imagining cultural communities and identities, and new ways of combining more locally nuanced ideas, values and identities (Shi 2014).

\section{Social media, globalisation and culture}

Blommaert $(2010,1)$ pointed out that globalisation does not lead to a 'global village' but to a complex web of parts, interconnected in different ways and to different degrees. And with new forms of connections and communication possible through social media, this transformation calls us also to re-think the static models that we have been using. For Blommaert, it calls for a whole new vocabulary and new kinds of arguments to explain what we are seeing. Multicultural discourse studies needs to study social media to look at these more or less interconnected parts, at the way that ideas and values are shared or not shared, and consider the linguistic tools and modes deployed to do so. And importantly, it needs to engage with the wider issue of power. We live in a world dominated by some key kinds of power relations, specifically with the continued dominance and global spread of free-market capitalism. What may not be so important is how and if people are different, but the nature of the wider power relations that they inhabit and how these may be influenced by shifts in the communications landscape. In this world where social media are fused into everyday lives, this is a crucial part of this study, but which demands new ways of thinking. Later in this introduction I want to return to the kinds of power interests scholars identify as driving social media platforms.

Globalisation has also brought population shifts and migration, although it is often the migrant wage labourers who are the least rewarded by these shifts. These too involve issues of intercultural communication, as migrants use social media to link with more established migrants and foster new ties, which can aid and make the whole process much easier (Dekker \& Engbersen 2014) and faster, while at the same time providing an 'ambient' sense of home (Komito 2011, 1075). Charmarkeh (2013) shows how Somali refugees used Facebook in cybercafes to maintain contacts with other refugees met while in transit countries, and also to seek out contacts and romantic connections once in Europe. It has also been shown how diasporic social media groups can become highly radicalised and xenophobic (Conversi 2012). But migration can also create a situation in which existing citizens feel there is need to compete for material and symbolic resources (van Dijk 1996), sometimes leading to surges in interest in far right parties. But overall, these too involve interplays of worldviews, values and concepts, yet are played out under the dominant system of the ideology of neoliberalism, where concerns and fears are 'shared' and 'liked' through the social media embedded in the lives of the participants (Correa et al. 2010).

Castells $(2000,3)$ once argued that in a world of cross-national media flows, where former institutions break down, the search for identity becomes a key source of social meaning. And it seems that for many, as Livingstone (2008) suggests, creating and networking online content is becoming an integral means of managing one's identity, lifestyle and social relations. Some theorise the very use of sites as fundamentally 
performative acts (Cover 2012). Social media are one place where we can study just how this plays out. Particularly, as some scholars have argued, this has been accompanied with massive shifts in what people present about themselves for public knowledge (Nussbaum 2007). And certainly what is clear from studies of social media is that it is used for a combination of identity construction, the maintenance of social relationships and also to engage with more socially relevant matters. All of the papers in this special edition, despite their wide range of interests and theoretical approaches, point to such combinations.

\section{Social media and cross-cultural sharing}

De Zuniga et al. (2012) argue that the growing popularity of social media has created a debate: Do these Internet services contribute to society by allowing people to become informed, find common causes and participate in public life more often (e.g. Bennett 2008)? In this sense, is there a place for greater cross-cultural sharing? Or do they foster shallower relationships, distract people from public affairs and deepen their political and civic disengagement (e.g. Hodgkinson 2008)? As such, do social media lead to increasingly disengaged and insular forms of ideas, values, concepts, worldviews and means of realising these? Social media are social, but only in an immediate sense. The works of Lindgren (2010) and Georgakopoulou (2014) suggest that discussions of sociopolitical issues online do not deal with actual details but rather seek to frame events into pre-existing personal interests and alignments. Some scholars are more optimistic. Hilbert (2009) argues that people may well use social media for personal identity construction, but they may still use, contribute and share information that has civic relevance. It is to this kind of debate that two papers in this collection, by Way, in his study of YouTube posts about political protests in Turkey, and by Thulfiqar, about political views on Facebook in Iraq, make less than optimistic contributions.

Social theorists make some important observations about the wider shifts that online interactions may both be part of and a symptom of. Žižek (1997) pointed to his concerns that language in forums and blogs ceases to be 'subjectivized'. Simply by this he meant that users of a forum do not have to stand by what they say. They can intervene and then disappear, and can simply unhook if they do not like a response or want to escape the consequences of what they have said. An exit from social media is always just a click away. Users can leave a harsh comment and then come back several days later to see its effects. Dean (2010) points to the way that this can lead to discussion threads quickly disintegrating. Members unsubscribe, feeling attacked and embarrassed. The imbalance between participants and lurkers, who may appear suddenly, in threaded discussions can also add to this problem. In fact, Johnson $(2001,143)$ argues that when you consider the proportions of lurkers to discussants in a particular forum it is in fact less interactive than a face-to-face lecture and much less so than a conversation around a dinner table. In the light of Blommaert's (2010) comments about the need for discourse studies to adapt, are new approaches and tools needed to deal with these changes?

Dean (2010) adds a further point as regards this tendency to find snark comments on social media forums. She suggests that the Internet, the culture of engagement, of participation and of scan-and-go, has generated scepticism. This can be traced to the collapse of a sense of the 'big other', as Žižek (1997) would describe it, in other words a waning of the force of a central, forceful and institutional body of knowledge and is commonly agreed upon, or at least enforced, ideas, values and identities. Hardt and Negri (2000) saw this decline as resulting in a shift from a culture defined by the role of the citizen subject with more determined identifications to a culture that continually offers new 
ways to imagine ourselves. Dean $(2010,5)$ refers to this new situation as the culture of 'communicative capitalism'. In sum, a decline of 'the symbolic', or 'the decline of symbolic efficiency', to use Žižek's exact words, leaves a gap into which the images and effects of social media can be poured (Dean 2010, 5). On the one hand, this leads to a shift of more specialist kinds of forums and online spaces, often with their own more specialist language and terms that can easily exclude, annoy and confuse the outsider. On the other hand, Myers (2010) shows that successful blogs simply should have such specialist language as part of signalling a community of shared interest. Downey and Fenton (2003) point to a trend whereby political activist sites on social media can easily become radical, inhospitable ghettos. In this sense, much is to be established in a discursive sense as regards social media groupings, where more localised identities, ideas and values are celebrated as regards how esoteric there are. I will consider the research implications for such issues shortly. But clearly, this marks a requirement for the new kinds of approaches and tools, to which Blommaert refers, as we shift away from either highly personalised or mass media-based texts. And it also raises the question as to whether such shifts so adequately apply crossculturally. Do the arguments of Žižek and others apply so well in cultures with very different histories, ideas and values? Are these 'symbolic gaps' of the same order?

For Dean (2010), the decline of the symbolic has a further consequence which may have great relevance for intercultural communication through social media. She suggests that along with the demise of central authoritative ideas and identities that the Internet with its culture of engagement, of participation and of scan-and-go has generated scepticism. This scepticism means that users tend to regard comments always as opinion and not as information, which in turn means that we tend not to engage in receptive discussion but fall back on what is comfortable. All else is just opinion. And this too chimes with the kinds of wider changes observed by sociologists where there has been a shift to placing emphasis on the personal-as-political and where this is realised in a world where everything is supposed to be rewarding (Chaney 1996). Studies of the discourses in forum posts about important civic issues such as shootings in schools (Lindgren 2012) or pressing political events such as the economic crisis in Greece (Georgakopoulou 2014) become, rather, launch pads for existing views on gun control or xenophobic ideas about Germans. There was little evidence of receptivity. In this collection, the papers by Way and by Rasmussen both allow us to think a little more about these processes in very different contexts and on different social media platforms.

Understanding multicultural discourse now means, in part, acknowledging that acts of communication take place in these broader changes. Coupland (2010) pointed out that it was time for linguistics to engage with such wider forces sweeping the planet. Globalisations, shifts in technologies and forms of communication are all interlinked. While discourse analysts have skills specialist for closer analysis, the details found at this level will be shaped by the macro. And, crucially, this whole is driven by the forces of global consumer capitalism. I say a little more about this that follows, and why social media may tie into this in quite specific ways. It has been the case that discourse analysts have been less strong in connecting to these larger matters, such as the political economy of the media.

\section{The political economy of social media}

Early studies of the Internet were extremely optimistic, associating it with the liberation of the voice of the public taking power back from the arrogant big media (Bolter 1996) and how the structural features of online spaces facilitated self-presentation and 
expression (Papacharissi 2002, 2007). At least social media offer people an opportunity to share mostly unfiltered opinions and allow a greater variety of ideas and opinions to be available in the public sphere (Gillmor 2006). But more recently, scholars have turned their attention to the ways in which social media platforms directly profit from the activities of users, which in turn can provide information favourable to the interests of the state (Fuchs 2014), and have questioned how this is shaping their nature.

Social media are driven by the need to produce profits. As we use social media, such as Facebook or YouTube, scholars such as Van Dijck (2013) have shown, algorithms continually compute not only who our family, friends and former school friends are likely to be but also our consumer patterns and preferences. In fact, as Dean (2010) notes, it is no longer necessary to spy on activist groups as all the information is online.

And while social media present themselves in terms of connectivity and are always presumed a good thing, many platforms are in competition and lock each other out (Van Dijck 2013). Bigger platforms may include the buttons of other bigger platforms, but the aim is ultimately to lock users into their own chain of platforms $(2013,156)$. This is important to channel users from networking into consumer activity. Google aims to lock users into their own algorithmic flow of buttons.

This is a world of algorithms where our contacts and relationships with friends become the engine for commercial activities (Fuchs 2011). All our past behaviours will be converted to likely future behaviours. It is a world where we are continually being told what is already the most successful comment, idea, picture or story. Algorithms themselves become realisers of discourse, of forms of social relations, signalling up what your user community values, and signalling what kinds of ideas and attitudes are common across the section of connectivity. Things that get liked more get higher rankings and then will get more interest. They can then become high-profile, attracting further discussions and bringing into focus other similar content. The early optimistic view of social media may still carry as regards the flourishing of different points of view and the facilitation of unique specialised shared interest groups, but these remain largely hidden unless specific search terms are used (Dean 2010). What we find at the top is something else. In some ways, this is not unlike older big media. But again these processes are part of the ways in which media corporations seek to shape behaviours towards acts of consumption. What is different here is the micro way that personal and cultural tastes can be identified, fed back and used, as 'you may also like' fuses content, promotions, adverts and connections with other people and groups. Doctor (2010) has looked at the way the news industry is meeting this shift. Here, the decline of the symbolic is also evident at a practical and commercial level where news is selected and shaped, not for a citizen but through algorithms worked out through your patterns of connectivity. And as product information and ranking websites with their own consumer review link, using algorithms to Facebook and YouTube, users too become part of this chain of endorsement, which itself figures as an act of citizenship. Dean $(2010,31)$ suggests that these networks of communications circulate 'less as potential for freedom than as affective intensities produced through and amplifying our capture'. Niche communities that have more clearly established consumer patterns, or who perform the role of reviewer better, may even float to the surface more easily.

Scholars write of wider cultural shifts fostered by the Internet and particularly by Web 2.0. This shift is from big media that transmitted formal, more distant authoritative information to a relatively powerless receiver, to a new kind of cultural characterised by 'scan and go' (Dean 2012). As Yiqiong et al., in this collection, point out, this marks a 
shift in social relations from where big media can assume users will accept the position of the informed to one where they expect to be engaged, addressed and treated as 'knowers'.

In one of the earlier examinations of the potential of cyberspace, Gunkel and Gunkel (1997) argued that new worlds are invented with principles transcribed from old worlds and concluded that: "naming is always an exercise in power ... The future of cyberspace, therefore, will be determined not only through the invention of new hardware, but also through the names we employ to describe it.' (1997, 133). Couldry (2012) introduced the idea of 'media practice' to think about the way that media become incorporated into everyday lives in unremarkable and socially learned ways, such as 'searching', 'sharing', 'showing', 'being shown', 'community', the value of the 'latest update' and the 'new'. In critical discourse analysis, given the assumption of the clear relationships between language and concepts and social practices (Fairclough 2000), this would indeed have massive consequences as regards how we go on to organise our societies and the institutions we build (Kress 2010).

What Couldry (2012) wonders is how these media practices inform us about wider senses of our relationships with people, with the social and civic world. Concepts such as 'network' and 'making connections' have themselves become highly valued and are a common form of understanding the world, society and social relations. But are these the same as older terms like 'cooperation'? Pfeiffer $(2004,22)$ notes that the computer and social media are viewed as almost inventing things like interaction, communication and cooperation, as if they formerly did not exist. Nor is it true, Pfeiffer points out, that all computer and social media use are really interactive or communicative. Yet the rhetoric of the networked society, with its speed and connectivity, chimes with the values of innovation - the latest technology - and the value of communication, the value of speed. Žižek (1998), in fact, introduces the work 'interpassive' as a counter to 'interactive', to point to the casual and weakly engaged nature of many online relationships and activities. Dean (2010) too has pointed to the more passive nature of 'clickivism', as a form of replacing political activism, where platforms like Facebook allow users to click 'likes' in support of movements against major injustices - such as for the end of global capitalism.

Again, what is clear is that all this implies a challenge for the study of discourse and for multicultural discourse. In the 1990s and around the turn of the century, it was in vogue in the field of media studies to investigate the ways in which global media genres and formats disseminated more 'Western' or at least 'consumer capitalist' ideas, values and identities around the planet, asking how local cultures took these up and negotiated them (Featherstone et al. 2001). Social media provide a whole new set of resources to follow these processes and of course the demand that we develop the tools and concepts to do so.

So, in Couldry's (2012) sense, have these media practices helped to generate scepticism of, and a scan-and-go attitude to, information, a retreat into the comfort of being with those who share our existing opinions, un-receptiveness to new ideas online, a culture of not standing by our words? And in terms of the core questions of multicultural discourse studies, how does this influence and feed into the way people express cultural identities and engage with those of others?

In order to engage with multicultural discourse online, we need to be open to the challenge played by these shifts, or at least open to the fact that there may be such shifts that shape the nature of the deployment of language and other semiotic resources that we seek to study. Van Dijck (2013) reminds us that social media, structured by powerful platforms such as Facebook and Google +, have shifted in the last decade from a culture of connectedness to one of 'connectivity'. This connectivity is the culture characterised 
by the colonisation of terms associated with 'the social', 'sharing', and 'community'. This is done so in the direct cause of increasing the quantity of traffic that can be converted into packeted information.

For discourse studies, all of this is crucial to take on board for a number of reasons. Van Leeuwen and Wodak (1999) described discourses made up of kinds of 'scripts' that are the 'doings' of social practices. These are comprised of identities, ideas, values, actions, sequences of events, settings and times. To what extent can these 'media practices' of social media be found incorporated into the wider multicultural discourses that become realised on social media platforms like Facebook, Instagram and Twitter? What does acting in a network of social contacts actually mean in terms of scripts? Just as scholars call on more detailed empirical study of the ways in which the ideas, values and identities of international media interact with local contexts and local cultures (Aiello and Pauwels 2014), so too we need more work on the way that these new media practices now infuse, are transformed by or transform existing diverse cultural discourses.

\section{Identity, online performance and the relationship between the online and offline worlds}

One question for the study of social media discourse, from what we have so far said, involves the question of how online discourse relates to offline. What is the relationship to what people do, say and show - the concepts, values and discourse - online, to their offline lives, or even across social media platforms? The need to acknowledge the social goings on that lie behind texts has been something that discourse analysts have more widely acknowledged (Fairclough 2000; Richardson 2007) in order to more fully understand the nature and origins of the ideologies that can be revealed in texts.

Of course, a simple distinction between offline and online does not capture the complex way that social media have become so thoroughly embedded in the routines of everyday life (Bakardjieva 2005) as we become reliant on the Internet to accomplish basic daily tasks, do shopping, find a playground for the children, learn how to play the piano and check out a diagnosis for a rash on a child's foot. The online/offline distinction greatly inhibits our ability to describe and understand these communication processes. (Ellison et al. 2011). But this does not mean that we simply ignore any such relationships. For Thurlow et al. $(2004,75)$, the task is rather to look at how these social media are embedded in our everyday lives and also how our lives are embedded in social media. For discourse analysts therefore, this has consequences for what data are required and also for the tools of analysis.

Empirical studies have pointed to the great value of understanding online behaviour as it interrelates with the offline. One such case is research on language use and minority language, where it is important to relate the vitality of language use both in everyday use and in social media as regards lessons that can be learned from this for helping endangered languages (Cunliffe et al. 2013). Minority language may be used online while majority language is used offline (Fleming and Debski 2007).

Some scholars have pointed to the importance of the role of anonymity and how this influences behaviour, also in the case of anticipated subsequent face-to-face encounters (Ellison et al. 2006, 416) allowing them to make comments on the discrepancy between 'actual selves' and 'ideal selves' in people's online self-presentation. Although it seems that to the present, most of the research on such discrepancies has been done on Internet dating sites. Here it has been suggested that users tend to 'stretch the truth a bit' (Yurchisin et al. 2005, 742) in their online self-presentations, and also that they can give 
faithful representations of their selves, in order to avoid disappointments in subsequent offline meetings (Ellison et al. 2006). What seemed clear in interactions was that the nature of the lag in responses gave users time to carefully craft an attractive persona (Gibbs et al. 2006), which we might say is true of most social media even though in Facebook and Twitter anonymity is less of an issue.

However, Zhao et al. (2008) made a slightly different argument. Users saw their constructions of online 'hoped-for possible selves' (Yurchisin et al. 2005) as indeed part of their overall identities. It appears that Facebook users, where of course there is no anonymity, "predominantly claim their identities implicitly rather than explicitly; they "show rather than tell" and stress group and consumer identities over personally narrated ones' (Zhao et al. 2008, 1816). But what is certain is that such issues of idealised identities should be of interest to a study of multicultural discourses.

Researchers were calling for more research to unpack the ways in which identities play out in face-to-face and online contexts (Ellison et al. 2011). In the context of Facebook, much research orbited around the way that profiles were used to increase levels of social capital (Burke et al. 2010, 2011; Ellison et al. 2007; Valenzuela et al. 2009), a form of capital that describes resources embedded in social relationships and interactions within a network (Lim 2012). Such social capital can then transfer to face-toface contexts (Hampton et al. 2011). But it was clear that this needed tying to specific kinds of instances, rather than dealing more abstractly with the issue of social capital. For the study of discourse and identity, for example, we would want to know more about what resources and what kinds of identity characteristics were legitimised or delegitimised, for example.

Work on Twitter has also placed identity and self-presentation at its heart. Murthy (2012), for example, has drawn on the likes of Goffman (1981) and Bourdieu (1984) to look at the way that Tweeting about the banal, even about what you had for breakfast, is about self-affirmation and signals of being an engaged user. This was a time when Twitter had high cultural capital, was able to signify 'debate' and was popular with professional middle classes. This was partly as Twitter was a social networked media sending messages out to be forwarded and responded to by anyone, whereas social networked media like Facebook tended to be more about an extension of face-to-face relationships (Murthy 2012). Page (2012) has also looked at Twitter in terms of it being a 'linguistic marketplace' where people carry out a process of self-branding - although she views this 'synthetic personalization' (Fairclough 1989) very much as the same thing found in mainstream media talk. From the point of view of critical discourse analysts, such identity construction and self-presentation are important not only in themselves, but rather as these serve to position people against others, as part of processes of evaluation and legitimisation of wider kinds of identities and social processes.

Murthy $(2012,1063)$ sees a further shift through social media drawing on Turner's (2010) idea that contemporary media forms have taken a 'demotic turn'. Ordinary people have become increasingly visible and have become a major part of media content. They are the topic of TV shows and, themselves, are able to break news or provide the mobile phone camera footage of an explosion. But Turner sees this not as a form of democratisation. In mainstream media, the symbolic representation of these people is highly controlled. Even in social media, debates can happen very close to existing frames of reference often laid out by traditional sources of information and by dominant discourses (Murthy 2012). For example, 'trending' topics on Twitter will be based around breaking news events, as defined by mainstream media, and often contain links to full articles. Commentaries on the production of citizen-generated images circulated in social 
media, of conflicts and major events, on the one hand point to the way alternative viewpoints can emerge from societies where they are normally suppressed, as in the Iranian revolution (Gillmor 2011). But, on the other hand, this stream of images tends to produce the dominant frames of reference, into which we have been tutored by mainstream news media. Political uprisings will show close-ups of shouting people and give a sense that we are being taken close to the raw events, but they will tell us nothing about the complexity of the events (Cottle 2009).

Murthy (2012) suggests that perhaps we see Twitter and Facebook as part of what Therborn (2000, 42) calls the 'event society' or what Huyssen $(2000,25)$ calls the 'society of experience': we appear to, need to, focus upon, privilege and base our debates around, a stream of transient or trivial events. To a large extent these can be considered to be 'pseudo events' (Katz and Dayan 1985), based around immediate yet trivial occurrences, consumption of goods, and cultural events along with generic news stories. To some extent, this appears reminiscent of the arguments of Adorno and Bernstein (2001). They noted that social media should be studied as regards the way they are linked into the wider consumer and culture industries. Murthy $(2012,1064)$ notes that trending topics on Twitter are usually things like the music people are listening to, hated celebrities or favourite book titles that never made it to the shelf. For Dean (2010), this sits alongside commentaries of what someone is doing or how they feel at any given moment - what she says is blogging stripped to its most banal and repetitive. Although from the point of view of the discourse analyst, it is in such apparently banal things that the political, that the signals of wider social relations, can be best located (Bourdieu 1984).

Scholars have also been critical of the basic effects of social media use on everyday linguistic skills, of our very vocabulary, and ability to use grammar and to spell (Tucker 2009). In response, it can be argued that these share the more truncated in informal characteristics of face-to-face conversations. And in sociolinguistics we are beginning to understand more about the novel ways in which language is used in social media and how users adapt (Herring 2008).

Of course, we can find more positive accounts of social media and its links with the offline world. Scholars have linked social media use and information gathering to civic and political participatory behaviours offline (De Zuniga et al. 2012). It may be that people surely use social media for social relationships or entertainment, but people who have an interest in social and political issues are highly likely to also contribute and share information that is public-oriented in nature (Hilbert 2009). A study of the 2008 US presidential election showed that Facebook users shared links to news organisations such as CNN, the New York Times and the Huffington Post as well as cross-posted comments on their own Facebook profiles and on the main candidates' Facebook profiles (Robertson et al. 2010).

The most impressive online-offline link made by scholars has been related to protest movements, with wild celebrations that social media can simply bring light to the democratic nature of people, and others pointing to the need for more careful and thorough study. And this too points to grasping the relationships between online and offline identities and discourses.

Scholars have discussed the use of social media to mobilise people in anti-capitalist movements and environmental rallies (Bennett and Segerberg 2012; Howard and Hussain 2011). Social media are described as the main force behind the popular movement against authoritarian regimes in the Middle East and North African region (Cohen 2011; Webster 2011). Twitter, in particular, has been pinpointed as the fastest and most critical campaign tool for reaching and mobilising people, for gathering data and responding to public 
reactions (Parker 2012; Vergeer and Hermans 2013). Twitter was used not only to foster revolution through activism but also to recruit, as well as radicalise protesters and militants (see Gonzalez-Bailon et al. 2012).

Others have been more sceptical about just how much revolutions have been related to Twitter and Facebook (Rich 2011; York 2011 as cited in Lim 2012), and these observations are important to the status that we attribute to online discourse. Harsher critics pointed to the ways in which Twitter, as regards the Egyptian conflict, as in Iran, was more influential in fostering support outside of the countries (see Cottle 2011).

Lim (2012) gives a highly useful analysis, showing the rewards of combing analysis of online activity and offline situations. Her argument is that it is not true that the Egyptian revolt was a 'social media revolution', but rather better said that social media was one important tool. Quite simply, the means of communication are not enough. To draw on two of Lim's (2012) points, in the first place, it is well know that 'biographical availability' is needed to mobilise individuals to such social upheaval (McAdam 1986; Tindall 1994; Tindall and Bates 1998, cited in Lim 2012, 234). In the case of Egypt, a third of its population was under 30, without family responsibilities, experiencing massive unemployment. Simply, a large section of the population had little to lose. In addition, there had been extensive use of the Internet in the form of blogging and online newspapers since around 2005. But there had been no strong common message to bring diverse interest groups together. This had later been achieved at the time of the revolution. Lots of it was done using different kinds of social media, but it needed much ground work, political know-how and the right kind of people (Lim 2012, 244).

The celebration of the Twitter revolution could partly be explained by the way journalists focused on Tweets in English available at the time (Rothkopf 2009), who were little connected to more grass-roots aspects of the upheaval. For the study of multicultural discourse on social media, what this means is simply that we really need to produce studies that do not treat the online in isolation. What we learn from the papers by Way, Chiluwa and Thulfiqar in this collection is that much identity work done on social media is a process of motivated persuasion, even though there are claims of being the voice of a community.

\section{This special edition}

The collection of articles in this special edition approach multicultural social media discourse in very different ways. They point to the vast areas where multicultural discourse studies can work, bringing skills of more detailed forms of documentation and analysis of complex and emerging communicative forms - in one sense all the ambiguities of former studies of 'identity' and 'culture' are present, but realised in new ways.

What we also see is that all the papers link into different bodies of literature. They use different models and point to how this project must be multimodal, and that we really must place analysis on the details of texts in broader contexts of production, of the political economy of the media and also into the everyday lives of users. We must also avoid working in a way which isolates single instances of social media use, or making generalisations about 'social media' from one specific type of platform which itself is always evolving. It would also be helpful to avoid highly generic and misleading terms like 'digital media', or 'digital discourse'. The papers by Way, Thulfiqar and Chiluwa use different approaches to look at the ways in which different political groups, or allegiances, use social media. Way offers a multimodal critical discourse analytical approach to analyse a Turkish YouTube protest pop video and the comments that are 
posted; Thulfiqar draws on the concept of delegitimisation from critical discourse analysis to look at how socio-political communities in Iraq manoeuvre for power online; and Chiluwa takes a sociolinguistic approach to how extremist groups present themselves and the wider community in Nigeria. All place their analyses with specific political situations. Rasmussen takes a discursive psychology approach to look at Twitter responses to a terror attack in Norway, and posts are characterised through suspicion of authorities and ethic labelling. Yiqiong et al. carry out a multimodal discourse analysis to look at how social media involve shifts in visual forms of address, embodying many of the kinds of shifts in identity and knowledge status discussed in this introduction. Vessey looks at social media as a 'barometer', gauging opinion against minority language ideologies in mainstream newspapers, and provides an interesting look at the way different discourses emerge and interrelate across media.

These papers also point to the fact that we must decentralise both what we study and the theories that we use to do so. What is meant by democracy, journalism, community and justice around the world may have much in common, especially as global capitalism expands. But they also will always have, at least, local accents and be characterised by transformations.

But the most salient point for me is that the changes we are seeing are not just about shifts in the use of grammar, an increase in the use of multimodal resources or new forms of collective mobilisation. Rather, these changes point to wider shifts in culture: globalisation, the demise of more centralised authoritative knowledge, shifts in a whole range of ideas and values of which concepts like 'networked' and 'innovation' are a part. Mumford (1934) warned against viewing such things in isolation from the greater sweep of historical change. Our culture may now prize social media and its connectivity because of other pathways of value change that lead us here, and not because they have value in themselves. Put simply, we will not find the answer to many of our question in texts alone. Coupland (2010) has made the point clear that sociolinguistics, for example, must engage with and have something to say about these wider forces. This is why here I wanted to take small steps in connecting with some of the wider ideas and theories of social media.

\section{Disclosure statement}

No potential conflict of interest was reported by the author.

\section{Notes on contributors}

GWEN BOUVIER (Ph.D.) lectures in New Media at Zayed University (UAE). Her research interests are social media, discourse and identity, news and representation. Her most cited paper is: 'How Facebook users select identity categories for self-presentation', in Multicultural Discourse (2012). Other recent papers are 'What is a discourse approach to Twitter, Facebook, YouTube and other social media: connecting with other academic fields?' in Multicultural Discourse (2015) and 'British press photographs and the misrepresentation of the 2011 "uprising" in Libya' in Visual Communication (2014). She is on the advisory board of a number of international peer reviewed journals, such as Media, Conflict and Society, and is editorial assistant at the journal Social Semiotics.

\section{References}

Adorno, T., and J.M. Bernstein. 2001. The culture industry: Selected essays on mass culture. London: Routledge. 
Aiello, G., and L. Pauwels. 2014. Special issue: Difference and globalization. Visual Communication 13, no.3: 275-285.

Bakardjieva, M. 2005. Internet society: The Internet in everyday life. London: Sage.

Bennett, W.L. 2008. Changing citizenship in the digital age. In Civic life online: Learning how digital media can engage youth, ed. E.L. Bennett, 1-24. Cambridge: MIT Press.

Bennett, W.L., and A. Segerberg. 2012. The logic of connective action. Information, Communication \& Society 15, no.5: 739-768.

Blommaert, J. 2010. The sociolinguistics of globalization. Cambridge: Cambridge University Press.

Bolter, J.D. 1996. Writing space: Computers, hypertext, and the remediation of print. London: Routledge.

Bourdieu, P. 1984. Distinction. A social critique of the judgment of taste. Cambridge, MA: Harvard University Press.

Burke, M., R. Kraut, and C. Marlow. 2011. Social capital on Facebook: Differentiating uses and users. Paper presented at ACM CHI Conference on Human Factors in Computing Systems, May $7-12$, in Vancouver, BC, Canada.

Burke, M., C. Marlow, and T. Lento. 2010. Social network activity and social well-being. Paper presented at ACM CHI Conference on Human Factors in Computing Systems, April 10-15, in Atlanta, GA, USA.

Castells, M. 2000. The rise of the network society. Malden, MA: Blackwell.

Chaney, D. 1996. Lifestyles. London: Routledge.

Charmarkeh, H. 2013. Social media usage, tahriib (migration), and settlement among Somali refugees in France. Refugee 29, no.1. http://pi.library.yorku.ca/ojs/index.php/refuge/article/view/ 37505 .

Cohen, R. 2011. Facebook and Arab dignity. New York Times, January 24. http://www.nytimes.com/ 2011/01/25/opinion/25iht-edcohen25.html.

Conversi, D. 2012. Irresponsible radicalisation: Diasporas, globalisation and long-distance nationalism in the digital age. Journal of Ethnic and Migration Studies 38, no.9: 1357-1379.

Correa, T., A.W. Hinsley, and H.G. De Zuniga. 2010. Who interacts on the web?: The intersection of users' personality and social media use. Computer in Human Behavior 26, no.2: 247-253.

Cottle, S. 2009. Global Crisis Reporting. Maidenhead: OUP.

Cottle, S. 2011. Media and the Arab uprisings of 2011: Research notes. Journalism 12, no.5: 647-659.

Couldry, N. 2012. Media, society, world: Social theory and digital media practice. London: Polity.

Coupland, N. ed. 2010. Handbook of language and globalization. Malden, MA and Oxford: WileyBlackwell.

Cover, R. 2012. Performing and undoing identity online: Social networking, identity theories and the incompatibility of online profiles and friendship regimes. Convergence 18, no.2: 177-193.

Cunliffe, D., D. Morris, and C. Prys. 2013. 'Young bilinguals' language behaviour in social networking sites: The use of Welsh on Facebook. Journal of Computer-Mediated Communication 18, no.3: 339-361.

Dean, J. 2010. Blog theory. London: Polity.

Dean, J. 2012. The communist horizon. London: Verso.

Dekker, R., and G. Engbersen. 2014. How social media transform migrant networks and facilitate migration. Global Networks 14, no.4: 401-418.

De Zuniga, H.G., N. Jung, and S. Valenzuela. 2012. Social media use for news and individuals' social capital, civic engagement and political participation. Journal of Computer-Mediated Communication 17, no.3: 319-336.

Doctor, K. 2010. Newsonomics: Twelve New Trends That Will Shape the News You Get. London: St Martin's Press.

Downey, J., and N. Fenton. 2003. New media, counter publicity and the public sphere. New Media and Society 5, no.2: 185-202.

Ellison, N.B., R. Heino, and J. Gibbs. 2006. Managing impressions online: Self-presentation processes in the online dating environment. Journal of Computer-Mediated Communication 11, no.2: 415-441.

Ellison, N.B., C. Steinfield, and C. Lampe. 2007. The benefits of Facebook "friends": Social capital and college students' use of online social network sites. Journal of Computer-Mediated Communication 12, no.4: 1143-1168. 
Ellison, N.B., C. Steinfield, and C. Lampe. 2011. Connection strategies: Social capital implications of Facebook-enabled communication practices. New Media \& Society 13, no.6: 873-892.

Fairclough, N. 1989. Language and power. London: Longman.

Fairclough, N. 2000. New language, new labour. London: Routledge.

Featherstone, M., S. Lash, and R. Robertson (eds.). 2001. Global modernities. London: Sage.

Fleming, A., and R. Debski. 2007. The use of Irish in networked communications: A study of schoolchildren in different language settings. Journal of Multilingual and Multicultural Development 28, no.2: 85-101.

Fuchs, C. 2011. The contemporary world wide web: Social medium or new space of accumulation? In The political economies of media. The transformation of the global media industries, eds. D. Winseck and D.Y. Jin, 201-220. London: Bloomsbury.

Fuchs, C. 2014. Digital labour and Karl Marx. London: Routledge.

Georgakopoulou, A. 2014. Small stories transposition and social media: A micro-perspective on the 'Greek crisis'. Discourse Society 25, no.4: 519-539.

Gibbs, J.L., N.B. Ellison, and R.D. Heino. 2006. Self-presentation in online personals: The role of anticipated future interaction, self-disclosure, and perceived success in Internet dating. Communication Research 33, no.2: 152-177.

Gillmor, D. 2006. How to use Flickr: The digital photography revolution. Boston, MA: Thomson Course Technology.

Gillmor, D. 2011. Rodney King and the rise of citizen photojournalism. Mediactive, March 15. http://mediactive.com/2011/03/02/rodney-king-and-the-rise-of-the-citizen-photojournalist/.

Goffman, E. 1981. Forms of talk. Philadelphia: University of Pennsylvania Press.

González-Bailón, S., N. Wang, A. Rivero, J. Borge-Holthoefer, and Y. Moreno. 2012. Assessing the bias in samples of large online networks (working paper) http://arxiv.org/ftp/arxiv/papers/1212/ 1212.1684.pdf.

Gunkel, D.J., and A.H. Gunkel. 1997. Virtual geographies: The new worlds of cyberspace. Critical Studies in Media Communication 14, no.2: 123-137.

Hampton, K.N., C. Lee, and E.J. Her. 2011. How new media affords network diversity: Direct and mediated access to social capital through participation in local social settings. New Media \& Society 13, no.7: 1031-1049.

Hardt, M., and A. Negri. 2000. Empire. New York: Harvard University Press.

Herring, S.C. 2008. Computer-mediated discourse. In The handbook of discourse analysis, eds. D. Schiffrin, D. Tannen, and H.E. Hamilton, 612-34. London: Blackwell.

Hilbert, M. 2009. The maturing concept of e-democracy: From e-voting and online consultations to democratic value out of jumbled online chatter. Journal of Information Technology \& Politics 6 , no.2: 87-110.

Hodgkinson, T. 2008. With friends like these.... The Guardian. http://www.theguardian.com/ technology/2008/jan/14/facebook.

Howard, P., and M. Hussain. 2011. The role of digital media. Journal of Democracy 22, no.3: $35-48$.

Huyssen, A. 2000. Present pasts: Media, politics, amnesia. Public Culture 12, no.1: 21-38.

Johnson, S. 2001. Emergence: The connected lives of ants, brains, cities, and software. New York: Scribner.

Katz, E., and D. Dayan. 1985. Media events: On the experience of not being there. Religion 15: $305-314$.

Komito, L. 2011. Social media and migration: Virtual community 2.0. Journal of the American Society for Information Science and Technology 62, no.6: 1075-1086.

Kress, G. 2010. Multimodality. London: Routledge.

Larsson, S. 2009. The emerging economy of publications and citations. Nordisk Pedagogik 29, no.1: $34-52$.

Lim, M. 2012. Clicks, cabs, and coffee houses: Social media and oppositional movement in Egypt, 2004-2011. Journal of Communication 62, no.2: 231-248.

Lindgren, S. 2010. YouTube gunmen? Mapping participatory media discourse on school shooting videos. Media, Culture \& Society 33, no.1: 123-136.

Lindgren, S. 2012. Collective coping through networked narratives: YouTube responses to the Virginia tech shooting. In School shootings: Mediatized violence in a global age, eds. G.W. Muschert and J. Sumiala, 279-298. (Studies in Media and Communications 7) Bingley: Emerald Group. 
Livingstone, S. 2008. Taking risky opportunities in youthful content creation: Teenagers' use of social networking sites for intimacy, privacy and self-expression. New Media and Society 10, no.3: 393-411.

Mumford, L. 1934. Technics and civilization. New York: Harper.

Murthy, D. 2012. Towards a sociological understanding of social media: Theorizing Twitter. Sociology 46, no.6: 1059-1073.

Myers, G. 2010. The discourse of blogs and wikis. London: Continuum.

Nussbaum, E. 2007. The kids, The Internet, and the end of privacy. Say everything. New York Magazine, February 12. http://nymag.com/news/features/27341/index7.html.

Page, R. 2012. The linguistics of self-branding and micro-celebrity in Twitter: The role of hashtags. Discourse and Communication 6, no.2: 181-201.

Papacharissi, Z. 2002. The virtual sphere: The Internet as a public sphere. New Media and Society 4, no.1: 9-27.

Papacharissi, Z. 2007. The blogger revolution? Audiences as media producers. In Blogging, citizenship, and the future of media, ed. M. Tremayne, 21-39. London: Routledge.

Parker, A. 2012. In nonstop whirlwind of campaigns, twitter is a critical tool. New York Times. http://www.nytimes.com/2012/01/29/us/politics/twitter-is-a-critical-tool-in-republican-campaigns. html.

Pfeiffer, S. 2004. Arbeitsvermögen [Working Capacity]. Wiesbaden: VS Verlag für Sozialwissenschaften.

Richardson, J. 2007. Analysing newspapers. London: Palgrave Macmillan.

Robertson, S., R. Vatrapu, and R. Medina. 2010. Off the wall political discourse: Facebook use in the 2008 U.S. presidential election. Information Polity 15: 11-31.

Rothkopf, D. 2009. There's no such thing as a virtual revolution. Foreign Policy Magazine, June 17. http://foreignpolicy.com/2009/06/17/theres-no-such-thing-as-a-virtual-revolution/.

Shi-xu. 2013. Discourse and culture: From discourse analysis to cultural discourse studies. Shanghai: Shanghai Foreign Languages Press.

Shi-xu. 2014. Chinese discourse studies. Basingstoke: Palgrave Macmillan.

Therborn, G. 2000. At the birth of second century sociology: Times of reflexivity, spaces of identity, and nodes of knowledge. British Journal of Sociology 51, no.1: 37-57.

Thurlow, C., L. Lengel, and A. Tomic. 2004. Computer-mediated communication: Social interaction and the Internet. London: Sage.

Tucker, P. 2009. The dawn of the postliterate age. Futurist 43, no.6: 41-45.

Turner, G. 2010. Ordinary people and the media: The demotic turn. London: Sage.

Valenzuela, S., N. Park, and K.F. Kee. 2009. Is there social capital in a social network site? Facebook use and college students' life satisfaction, trust and participation. Journal of ComuterMediated Communication 14, no.4: 875-901.

van Dijk, T.A. 1996. Discourse, power and access. In Texts and Practices: Readings in Critical Discourse Analysis, eds. C.R. Caldas-Coulthard and M. Coulthard, 84-104. London: Routledge

Van Dijck, J. 2013. The culture of connectivity: A critical history of social media. Oxford: OUP.

Van Leeuwen, T., and R. Wodak. 1999. Legitimizing immigration control: A discourse-historical analysis. Discourse Studies 1, no.1: 83-118.

Vergeer, M., and L. Hermans. 2013. Campaigning on Twitter: Microblogging and online social networking as campaign tools in the 2010 general elections in the Netherlands. Journal of Computer-Mediated Communication 18, no.4: 399-419.

Webster, S. 2011. Has social media revolutionized revolutions? World News, February 16, 87, 15. http://www.jcunews.com/2011/02/16/has-social-mediarevolutionized-revolutions/.

Yurchisin, J., K. Watchravesringkan, and D.B. McCabe. 2005. An exploration of identity recreation in the context of Internet dating. Social Behavior and Personality 33, no.8: 735-750.

Zhao, S., S. Grasmuck, and J. Martin. 2008. Identity construction on Facebook: Digital empowerment in anchored relationships. Computers in Human Behaviour 24, no.5: 1816-1836.

Žižek, S. 1997. The plague of fantasies. London: Verso.

Žižek, S. 1998. The interpassive subject. Paris: Traversess. 